\title{
Effects of storage of fresh cassava in moist sawdust on the proximate chemical and functional properties of gari
}

\author{
Olumuyiwa Adekanmi Babarinsa, Isaac Babatunde Oluwalana, \\ Matthew Kolade Bolade
}

Federal University of Technology, Akure, Ondo state, Nigeria

Keywords:

Gari

Cassava

Root

Storage

Article history:

Received 19.04.2018

Received in revised form 03.06.2018

Accepted 29.06.2018

Corresponding author:

Olumuyiwa Adekanmi

Babarinsa

E-mail:

kanmibabarinsa@

gmail.com

DOI: $10.24263 / 2304-$

974X-2018-7-2-9

\section{Abstract}

Introduction. The research was carried out to evaluate the utilisation qualities of cassava roots stored in sawdust for gari production.

Materials and methods. A completely randomised design was used to investigate the effect of storage time on the results of processing gari. Fresh cassava roots were stored in sawdust for 12 weeks and gari which is a cassava product was produced every two weeks. The proximate composition, chemical composition and functional properties of the gari were determined.

Results and Discussion. Cassava major food product in Africa is gari, the latter covers about $70 \%$ of cassava use in human consumption. Cassava Manihot esculenta Crantz is a starchy root which is a highly perishable crop, it starts to deteriorate within two or three days after harvest if not stored or processed. This study investigates the quality of gari produced from stored cassava roots.

The results show that there were significant differences in the proximate composition of gari samples in terms of the ash content, moisture content, fat content, fibre, protein and carbohydrate $(\mathrm{p}<0.05)$. The $\mathrm{pH}$, TTA, $\mathrm{HCN}$ values of the gari ranged from 3.9 to $4.89,0.77$ to $0.9 \%$, and 0.25 to $0.33 \mathrm{mg} / \mathrm{kg}$ respectively. Also, there were significant differences $(\mathrm{p}<0.05)$ in the bulk density, water absorption capacity and swelling index, which ranged between 7.79 and $8.169 \mathrm{~g} / \mathrm{cm}^{3}, 199.18$ and $311.11 \mathrm{ml} / \mathrm{g}$, and 3.13 and 3.96 , respectively.

Conclusion. Cassava roots stored for about 12 weeks will still produce a good quality gari. 


\section{Introduction}

Gari is the most popular of the cassava products in Africa (Oluwole et al., 2004). Gari is a creamy-white, granular flour with a slightly fermented flavor and a slightly sour taste made from fermented, gelatinized fresh cassava tubers (Sanni et al., 2008). It is consumed as processed or reconstituted with hot water to give a dough-like paste called $E b a$.

Cassava is different from other major root crops in that its roots are not organs of dormancy, making the pre-process storage a main problem of its utilisation (Karim et al., 2009). NSPRI (1995) reported that the shelf life of cassava can be extended to about 8-10 weeks, based on high visual acceptability of stored cassava root in transverse section.

However, storage and utilisation quality of cassava has not been established for that length of time except for Akingbala et al., (2005) and Karim et al., (2009) who only investigated the samples after 3 and 2 weeks of storage respectively.

However, there is need for more studies to establish other limits and benefits of the recommended methods in terms of the functional, chemical, and physical properties of the stored cassava and its products.

Hence, the aim of this work is to evaluate the utilisation quality of cassava roots stored in sawdust for gari production.

\section{Materials and methods}

\section{Storage of Cassava roots}

12-months-old (var. TME 7), was harvested from Lasuju farm settlement in Asa LGA of Kwara State, Nigeria. The storage was done using the storage method described by Babarinsa and Oluwalana (2018), the root were arranged in layers and surrounded with moist sawdust so that no two tubers touched one another.

\section{Gari production}

$15 \mathrm{Kg}$ of stored cassava was processed into gari for analysis every two (2) weeks. Gari was produced by the process described by Onyekwere et al. (2004). All the gari samples were prepared by one commercial gari processor, this is to avoid variability in processing. The cassava root of was peeled manually using sharp stainless steel knife. The peeled roots were washed and grated in a diesel powered grater. The grated meal was dewatered and was allowed to ferment for 72 hours. The pressed cake was broken and sieved with a wire mesh screen. The sieved pulp was garified using a wide shallow cast iron pot and stirred continuously over a low fire until well dried. It was then cooled, packaged, labeled and sealed.

\section{Laboratory Analysis}

The proximate analysis (moisture content, ash content, fat content, fibre, protein and carbohydrate) was carried out according to AOAC (2005). Estimation of hydrogen cyanide was done using silver-nitrate volumetric analysis described by Oboh et al., (2002), while the $\mathrm{pH}$ and Total titratable acidity (TTA) as lactic acid was determined according to AOAC, (2005). Bulk density swelling index, water absorption Capacity of the sample was determined using the method described by AOAC (2005), Ukpabi and Ndimele (1990) and Ogungbenle et al. (2002) respectively. 


\section{Statistical analysis}

A Completely Randomised Design was used to investigate the effect of storage time on the analytical determinations. Results from the analysis were subjected to analysis of variance $(p<0.05)$. The Duncan $(1955)$ multiple range test was then used to separate means. All analysis were in triplicate and Statistical analysis was done using SPSS 17.

\section{Results and discussion}

\section{Moisture content}

The moisture content of the gari was significantly affected by the processing rather than storage time $(\mathrm{p}<0.05)$, the values was generally low and were between 8.11 and $8.59 \%$ (Table 1). The moisture content of all the gari samples were below the $10 \%$ stipulated standard of the revised regulation of the Standard Organization of Nigeria and the export range of 6-10\% (Sanni et al., 2005).

Moisture is a significant parameter in cassava flour storage, high moisture greater than $12 \%$ allow for microbial growth. This is because moisture content and water activity of foods affect the progress of their chemical and microbiological spoilage reactions and thus low levels are favourable and give relatively longer shelf life. All the gari will be able to store for 7 months because their moisture contents were below the levels reported by Ukpabi and Ndimele (1990, who found that gari samples with a moisture content of $<16 \%$ but $>13 \%$ could be stored for 2-7 months without mould infestation. All the samples had good moisture levels and hence have the potential for better shelf life.

\section{Ash content}

The gari samples were significantly different $(\mathrm{P}<0.05)$, with the gari produced after Week 8 having the lowest value of $1.28 \%$ and Week 6 having the highest value of $3.34 \%$. The values obtained in weeks $0,2,8$ and 10 were comparable to the range of $1 \%$ to $2.84 \%$ dry weight reported by Aryee et al. (2006) and the range of values reported by Okolie et al. (2012) in their comparative study of different gari samples in Nigeria.

Ash content, which is a measure of the mineral element contents in the plant, is said to depend on the mineral contents of the soil. The slight differences in the ash content must have been due to processing. During processing, the dewatering of the grated cassava mash by pressing with a screw press may have resulted in loss of some minerals via the expressed water thereby reducing the ash content. The reduction may also be due to degradation of naturally occurring chemicals and loss due to spoilage (Ajala et al. 2012).

\section{Fat content}

All the gari had low fat content with the highest being $0.42 \%$. There were significant differences $(\mathrm{p}<0.05)$ in the fat content amongst the studied gari samples. The gari samples were in line with those of $0.1 \%$ to $0.4 \%$ reported by Charles et al. (2005) and $0.65 \%$ reported by Padonou et al. (2005).

\section{Fibre content}

Fibre content of the gari samples were in the range of 2.82-2.92\% (Table 1), which were significantly different between each other $(p>0.05)$. Week 0 had the lowest with 
$2.82 \%$, and Week 12 had the highest with $2.92 \%$. The gari samples were comparable in fibre content to the range of 1.61 and 3.63\% reported by Franklin et al., (2009) and close to the result of the studies by Oduro et al., (2000) on quality of gari from some selected gari processing centres in Ghana.

\section{Protein content}

The protein content of the gari investigated ranged from $0.78 \%$ to $0.98 \%$ (Table 1 ). There were significant differences amongst the studied samples and this may be attributed to storage time. This is in line with the protein content of cassava ranging between $1 \%$ and $3 \%$ on a dry matter basis, reported by Buitrago (1990). The increase in the protein content may likely be due to the presence of organisms that had been processed along with the cassava (Ajala et al., 2012).

\section{Carbohydrate content}

The carbohydrate content of the gari samples were significantly different $(p<0.05)$, having values ranging between $84.19-86.48 \%$ (Table 1). The values compared favorably with the values reported by Akingbala et al. (2005) and Karim et al., (2009) and about the same value reported by Rose-Monde et al., (2009). The high carbohydrate values obtained in this study suggest that cassava could be utilized as a reliable food and energy security crop (FAO, 2002).

\section{pH}

The storage time had significant $(\mathrm{p}<0.05)$ effect on the $\mathrm{pH}$ of the samples. The gari from Week 0 cassava root was more acidic, having $\mathrm{pH}$ of 3.90 while that of Week 10 was the lowest acidity with 4.89 (Table 1). Generally, there was decrease in the acidity as the storage time increases in the gari sample. The values agree with those of Oduro et al., (2000) for the normally fermented cassava gari ( $\mathrm{pH} 3.6$ to 4.0), and Bainbridge et al., (1996) who reported $\mathrm{pH}$ of $3.5-4.5$ for acid fermented product. The acidity of fermented cassava product has been found to be caused by the synthesis of lactates, acetates and some volatile organic acids (Oyewole and Odunfa, 1989) caused by microoganism such as Cornebacterium manihot, Geotriucm candida, Lactobacillus spp, which hydrolyze starch to this organic acids. The acid contributes to the desirable sourness of gari and is also an indication of the duration and effectiveness of the fermentation step in gari processing (Akingbala et al., 2005).

\section{Total titratable acidity}

The titratable acidity of the gari was significantly affected by the storage time $(\mathrm{p}<0.05)$. The total titratable acidity expressed as percentage lactic acid of gari samples was between the range of $0.76-0.90 \%$ (Table 1 ). The total titratable acidity agrees with the Codex standard of total acidity for gari which is between 0.6 and $1.0 \%$, expressed as percent lactic acid (Codex Alimentarius Commission, 1989) and the recommended standard of $0.6-1.2$ for cassava-gari by Oduro et al., (2000). Since changes in total titratable acidity is due to dissociation of the weak organic acids, mainly lactic and formic acids, Table 1 implies that the dissociation occurred and reached its optimum in the early week of storage, and subsequently there were poor or no dissociation. Fermentation is as a result of the lactic acid bacteria conversion of sugar content to organic acid (lactic acid) which consequently cause the increase in the total titratable acidity of the cassava mash (Akingbala et al,. 2005). The value ranged between 0.01- 0.16\% with Week 0 having the 
highest and was significantly different from the rest of the weeks. The total titratable acidity which ranged from of 0.01-0.16 compares favourably with the report of Akingbala et al., (2005) and Karim et al., (2009).

\section{HCN}

There were significant differences $(\mathrm{p}<0.05)$ among the gari samples, with Week 4 having the lowest value and Week 12 having the highest value with a range value of 0.25 0.33 (Table 1). The gari samples range of $0.25-.33$ and is far below the estimated lethal dose of 0.4-0.6 mg/kg reported for gari by Bokanga (1994).

\section{Bulk density}

Gari samples exhibited a decrease in bulk density value throughout the storage period and they differ significantly $(\mathrm{p}<0.05)$. The bulk density of gari produced from cassava roots ranged from $7.79-8.16$ (Table 1). The bulk density conforms favourably with the findings of Olaleye et al. (2014) which values ranges from $0.70-0.81 \mathrm{~g} / \mathrm{cm}^{3}$ and $0.61-0.77$ $\mathrm{g} / \mathrm{cm}^{3}$ for gari produced from bitter and sweet cassava varieties respectively but higher than those reported by Achinewhu et al. (1998) for six different cassava cultivars whose relative bulk densities ranged between 0.15 and $0.30 \mathrm{~g} / \mathrm{cm}^{3}$. The bulk density is a reflection of the load the samples can carry if allowed to rest directly on one another. Bulk density is affected by moisture and reflects particle size distribution of the gari products (Olaleye et al., 2014). Bulk density may also be attributed to high starch content in cassava which affect the mass and hence relative bulk density. According to Ukpabi and Ndimele (1990), good gari should have bulk density between 0.56 to $0.908 \mathrm{~g} / \mathrm{cm}^{3}$. High bulk density increases the rate of dispersion which is essential in the reconstitution of flours in hot water to produce dough.

\section{Water Absorption Capacity}

The Water absorption capacity of the gari was significantly affected by the storage time $(\mathrm{p}<0.05)$. Generally, the water absorption capacity reduces from 3.13 to $3.96 \mathrm{ml} / \mathrm{g}$ as the storage time increases though Week 8 was the lowest (Table 1). Water absorption capacity is a very important property of all flours or starches used in food preparations. The observed differences in water absorption capacity of the gari products as suggested by Olaleye et al., (2014) might be due to various factors such as particle size, amylose/amylopectin ratio and molecular structure. The larger the granular size, the greater the water absorption capacity while the higher the amylose levels, the lower the water binding capacity of starches (Akalu et al., 1998). Processing factors such as fermentation have also been found to increase water absorption capacity. Since polar groups of carbohydrates (for starchy foods like gari) are chiefly responsible for the binding of water, it therefore follows that the gari starch contains polar (hydroxyl) groups which are able to interact with water through hydrogen bonding (Obadina et al., 2008). It follows, therefore, that the higher the value of water absorption capacity, the greater the number of hydroxyl groups available to form hydrogen bonds with water (Obadina et al., 2008).

\section{Swelling Index}

Generally, the swelling index increased with increasing storage time ranging from 3.13-3.96. The values compare favourably with the Codex Alimentarius standard of 3, while a range of 2.7 to 3.3 was reported by Oduro and Clarke, (1999) and $2.84 \pm 0.26$ by Ajibola et al., (1987) in the Nigerian market Swelling index is the ability of gari to swell 
and this is influenced by the quantity and type of amylose and amylopectin present (Bainbridge et al., 1996) in the gari. Swelling index is very important because it indicates the degree of gelatinization of the gari sample and the rehydration characteristic. Swelling index reflects the extent of associative forces within the granules, thus, the higher the swelling index the lower the associative force (Sanni et al., 2001). According to Babarinsa (2011) a good quality gari should swell when soaked in water, to at least three times its dry volume because consumers demand gari with good swelling capability.

Table 1

Proximate, chemical and functional properties of the gari samples

\begin{tabular}{|c|c|c|c|c|c|c|}
\hline $\begin{array}{c}\text { Period of } \\
\text { storage }\end{array}$ & MC (\%) & ASH (\%) & FAT (\%) & CF (\%) & CP (\%) & CHO (\%) \\
\hline WEEK 0 & $8.41 \pm .09^{\mathrm{bc}}$ & $1.63 \pm .05^{\mathrm{e}}$ & $0.42 \pm .12^{\mathrm{a}}$ & $2.82 \pm .06^{\mathrm{b}}$ & $0.78 \pm .02^{\mathrm{d}}$ & $85.94 \pm .33^{\mathrm{b}}$ \\
\hline WEEK 2 & $8.44 \pm .03^{\mathrm{b}}$ & $2.38 \pm .04^{\mathrm{c}}$ & $0.33 \pm .02^{\mathrm{bc}}$ & $2.86 \pm .01^{\mathrm{ab}}$ & $0.85 \pm .05^{\mathrm{c}}$ & $85.13 \pm .14^{\mathrm{c}}$ \\
\hline WEEK 4 & $8.37 \pm .02^{\mathrm{c}}$ & $3.24 \pm .02^{\mathrm{a}}$ & $0.23 \pm .01^{\mathrm{d}}$ & $2.85 \pm .05^{\mathrm{ab}}$ & $0.91 \pm .01^{\mathrm{b}}$ & $84.41 \pm .04^{\mathrm{e}}$ \\
\hline WEEK 6 & $8.39 \pm .00^{\mathrm{bc}}$ & $3.34 \pm .02^{\mathrm{a}}$ & $0.27 \pm .01^{\mathrm{cd}}$ & $2.85 \pm .01^{\mathrm{ab}}$ & $0.97 \pm .02^{\mathrm{a}}$ & $84.19 \pm .06^{\mathrm{e}}$ \\
\hline WEEK 8 & $8.19 \pm .02^{\mathrm{d}}$ & $1.28 \pm .05^{\mathrm{d}}$ & $0.39 \pm .01^{\mathrm{ab}}$ & $2.82 \pm .03^{\mathrm{b}}$ & $0.83 \pm .02^{\mathrm{c}}$ & $86.48 \pm .02^{\mathrm{a}}$ \\
\hline WEEK 10 & $8.59 \pm .03^{\mathrm{a}}$ & $2.53 \pm .02^{\mathrm{b}}$ & $0.29 \pm .01^{\mathrm{cd}}$ & $2.86 \pm .01^{\mathrm{ab}}$ & $0.98 \pm .01^{\mathrm{a}}$ & $84.76 \pm .03^{\mathrm{d}}$ \\
\hline WEEK 12 & $8.11 \pm .01^{\mathrm{d}}$ & $3.24 \pm .01^{\mathrm{a}}$ & $0.21 \pm .01^{\mathrm{d}}$ & $2.92 \pm .08^{\mathrm{a}}$ & $0.87 \pm .01^{\mathrm{bc}}$ & $84.65 \pm .05^{\mathrm{de}}$ \\
\hline
\end{tabular}

\begin{tabular}{|c|c|c|c|c|c|c|}
\hline $\begin{array}{c}\text { Period of } \\
\text { storage }\end{array}$ & $\mathbf{p H}(\%)$ & TTA $(\%)$ & $\begin{array}{c}\mathbf{H C N} \\
\mathbf{( m g} / \mathbf{k g})\end{array}$ & $\mathbf{B D}\left(\mathbf{g} / \mathbf{c m}^{3}\right)$ & WAC $(\mathbf{m l} / \mathbf{g})$ & SI \\
\hline WEEK 0 & $3.90 \pm .02^{\mathrm{f}}$ & $0.77 \pm .01^{\mathrm{a}}$ & $0.30 \pm .01^{\mathrm{b}}$ & $8.16 \pm .05^{\mathrm{a}}$ & $311.11 \pm 5.13^{\mathrm{a}}$ & $3.14 \pm .02^{\mathrm{a}}$ \\
\hline WEEK 2 & $4.32 \pm .01^{\mathrm{b}}$ & $0.77 \pm .01^{\mathrm{a}}$ & $0.30 \pm .01^{\mathrm{b}}$ & $8.02 \pm .01^{\mathrm{b}}$ & $214.44 \pm 1.76^{\mathrm{c}}$ & $3.27 \pm .01^{\mathrm{b}}$ \\
\hline WEEK 4 & $4.27 \pm .01^{\mathrm{c}}$ & $0.80 \pm .00^{\mathrm{a}}$ & $0.25 \pm .00^{\mathrm{a}}$ & $8.03 \pm .00^{\mathrm{b}}$ & $220.81 \pm 2.27^{\mathrm{b}}$ & $3.21 \pm .01^{\mathrm{b}}$ \\
\hline WEEK 6 & $4.26 \pm .01^{\mathrm{c}}$ & $0.83 \pm .01^{\mathrm{b}}$ & $0.26 \pm .00^{\mathrm{a}}$ & $8.05 \pm .01^{\mathrm{b}}$ & $212.65 \pm .89^{\mathrm{cd}}$ & $3.15 \pm .01^{\mathrm{a}}$ \\
\hline WEEK 8 & $4.19 \pm .01^{\mathrm{d}}$ & $0.83 \pm .03^{\mathrm{b}}$ & $0.32 \pm .01^{\mathrm{ab}}$ & $7.79 \pm .00^{\mathrm{d}}$ & $199.18 \pm .17^{\mathrm{f}}$ & $3.13 \pm .01^{\mathrm{a}}$ \\
\hline WEEK 10 & $4.89 \pm .01^{\mathrm{a}}$ & $0.76 \pm .01^{\mathrm{c}}$ & $0.26 \pm .01^{\mathrm{a}}$ & $7.89 \pm .00^{\mathrm{c}}$ & $204.97 \pm .27^{\mathrm{e}}$ & $3.86 \pm .05^{\mathrm{c}}$ \\
\hline WEEK 12 & $4.11 \pm .01^{\mathrm{e}}$ & $0.90 \pm .01^{\mathrm{a}}$ & $0.33 \pm .00^{\mathrm{a}}$ & $7.90 \pm .00^{\mathrm{c}}$ & $210.10 \pm .01^{\mathrm{d}}$ & $3.96 \pm .01^{\mathrm{c}}$ \\
\hline
\end{tabular}

Values are means of triplicates and standard deviation. Mean values having different superscripts within the same column are significantly different $(\mathrm{p}<0.05)$.

\section{KEY}

$\mathrm{MC}=$ Moisture content $\mathrm{ASH}=$ Ash content

$\mathrm{FAT}=$ Fat contentCF $=$ fibre

$\mathrm{CP}=$ Protein content $\mathrm{CHO}=$ Carbohydrate

TTA $=$ Total Titratable Aciditity

$\mathrm{HCN}=$ Hydrogen Cyanide

$\mathrm{BD}=$ Bulk density

$\mathrm{WAC}=$ Water absorption capacity

$\mathrm{SI}=$ Swelling Index 


\section{Conclusion}

The study has shown that stored cassava root can produce good quality of Gari. The chemical values obtained in terms of the total titratable acidity and $\mathrm{pH}$ of gari produced compared effectively with the gari of published recommended values. HCN content were reduced during storage. The proximate composition was also comparable to the Week 0 sample and published recommended values. The functional properties in term of the swelling index, water absorption capacity and bulk density of the stored cassava also compared favourable with that of Week 0 and published recommendations.

Acknowledgement: The authors are grateful to Nigerian Stored Product Research Institute for cassava root storage facilities uses and the assistance of some technical staff in this work

\section{References}

1. Achinewhu SC, Barber LI, Ijeoma IO (1998), Physicochemical properties and garification (gari yield) of selected cassava cultivars in Rivers State, Nigeria, Plant Foods for Human Nutrition (Formerly Qualitas Plantarum), Springer Netherlands Publishers, 52(2), pp. 133-140.

2. Ajala L., Otutu, O., and Bamgbose, A. (2012), Effect of delayed processing on some physico-chemical properties of cassava starch. American Journal for Food Nutrition. 2(2), pp. 31-36, Doi: 10.5251/ajfn.2012.2.2.31.36

3. Ajibola O. O., Ige M. T. and Makanjuola G. A. (1987), Preliminary Studies of a New Technique of Cassava Mash Gelatinisation, Journal for Agricultural Engineering Research, 36, pp. 97-100.

4. Akalu G., Tufvesson F., Jonsson C., and Nair B.M. (1998), Physicochemical Characteristics and functional properties of starch and dietary fibre in grass pea seeds. Starch/Stärke, 50, pp. 374-382.

5. Akingbala J.O., Oyewole B.O., Uzo-Peters I., Karim7, O.R., Baccus-Taylor G.S.H. (2005), Evaluating stored cassava quality in gari production, Journal of Agricultural Environment, 3(1), pp. 75-80.

6. AOAC (2005), Official Methods of Analysis. 18th Edition, Association of Official Analytical Chemists, Washington.

7. Aryee F.N.A., Oduro I., Ellis W.O. and Afuakwa J.J. (2006), The physicochemical properties of flour samples from the roots of 31 varieties of cassava, Food Control, 17, pp. 916-922, DOI 10.1016/j.foodcont.2005.06.013.

8. Babarinsa, O.A. and Oluwalana, I.B. 2018. Effect of storage of fresh cassava in sawdust on Gari processing. Journal of Postharvest Technology, 6(1), pp. 57-62.

9. Babarinsa O.A., (2011), Quality assessment of gari produced from a gari frying machine. B.Sc Thesis. Department of Food Science and Technology, Federal University of Agriculture, Abeokuta, Nigeria.

10. Bainbridge Z., Tomlins K., Wellings K., Westby A. (1996), Methods for assessing quality characteristics of non-grain starch staple, Natural Resources Institute, Chatham.

11. Bokanga M., Ekanayake I. J., Dixon A.G.O., Porto M.C.M. (1994), Genotypeenvironment interactions for cyanogenic potential in cassava, Acta Horticulturae, 375, 
131-139, DOI: 10.17660/ActaHortic.1994.375.11

12. Buitrago J. A. (1990), La yucca em alimentacion animal. Publicacion 85, CIAT, Cali, Colombia.

13. Charles A.L., Sriroth K., Huang T.C. (2005), Proximate composition, mineral contents, hydrogen cyanide and phytic acid of 5 cassava genotypes, Food Chem, 92, pp. 615-20. DOI: 10.1016/j.foodchem.2004.08.024.

14. Codex Alimentarius Commission (1989), Codex Standards for miscellaneous products Joint FAO/WHO Food Standards Programme (Suppl. 1) to Codex Alimentarius, xii, Rome.

15. Duncan D. B. (1955), Multiple Ranges and Multiple F-tests. Biometrics, Vol. II, pp. $1-42$.

16. FAO (2002), Agricultural Statistics. Food and Agricultural Organization of the United Nations. Rome [29 May 2004].

17. Franklin B.A, Ibok O., William O.E., Osei S.K. (2009), Principal component analysis and age at harvest effect on quality on gari from four elite cassava varieties from Ghana, African Journal of Biotechnology, 8(9), pp. 1943-1949, DOI: 10.5897/AJB09.109.

18. Karim O.R., Fasasi O.S., Oyeyinka S.A. (2009), Gari yield and chemical composition of cassava stored using traditional methods, Pakistan Journal of Nutrition, 8(12), pp. 1830-1833, DOI:10.3923/pjn.2009.1830.1833

19. NSPRI (1995), National Training Workshop for Women-In-Agriculture. Organized by Nigerian Stored Products Research Institute, pp. 67-71

20. Obadina A.O, Oyewole O.B., A. A. Ayoola (2008), Quality Assessment of Gari produced using Rotary dryer. Food processing: methods, techniques and trends, Nova Science Publishers.

21. Oboh G., Akindahunsi A.A, Oshodi A.A. (2002), Nutrient and anti-nutrient content of Aspergillus niger fermented cassava products (flour and gari), Journal Food Composition Analysis, 15, pp. 617-176, DOI: 10.1006/jfca.2002.1065.

22. Oduro I., Brian Clarke (1999), The quality Assessment of gari produced by using microwave energy, International Journal of Food Science and Technolgy, 34, pp. 365-370, DOI: 10.1046/j.1365-2651.1999.00282.x

23. Odur I., Ellis W.O., Dziedzoave N.T. (2000), Quality of Gari from selected processing zones in Ghana. Food Composition, 2, pp. 297-303, DOI: 10.1016/S09567135(99)00106-1.

24. Ogungbenle H.N., Oshodi A.A., Oladimeji M.O. (2002), Effect of salt on the functional properties of benniseed (Sesanum radiatum) seed flour, Internation Journal Food Science and Nutrition, 53, pp. 5-14, DOI: 10.4172/2157-7110.1000645.

25. Okolie N.P, Brai M.N., Atoyebi O.M. (2012), Comparative study on some selected Garri samples sold in Lagos Metropolis, Journal of Food Studies, 1(1), DOI: 10.5296/jfs.v1i1.1947.

26. Olaleye O. O., Otunola E. T., Oyebanji A. O., Olatilewa M. O., Adegboye A. Y., Awosupin E. E. (2014), Effects of Storage Method on Functional and Pasting Properties of Cassava Roots Product, International Journal on Applied Research and Technology, 3(2), pp. 97-105.

27. Oluwole O.B., Olatunji O.O., Odunfa S.F. (2004), A process technology for conversion of dried cassava chips into gari, Nigerian Food Journal, 23, pp. 65-73, DOI: 10.4314/nifoj.v22i1.33570 
28. Onyekwere O.O., Akinrele I.A., Koleoso O.A., Heys G. (2004), Industrialization of gari fermentation. In, pp. Steinkraus, K.H., ed. Industrialization of Indigenous Fermented Foods, 2nd Edition. Marcel Dekker Inc., New York and Basel.

29. Oyewole O.B, Odunfa S.A., (1989), Effect of fermentation on the carbohydrate, mineral and protein contents of cassava during fufu production, Journal Food Composition Analysis, 2, pp. 170-176, DOI:10.1016/0889-1575(89)90078-1

30. Padonou, S.W., Nielsen, D.S., Akissoe, N.H. Hounhouigan, J.D., Nago, M.C. and Jakobsen, M. (2005), Development of starter culture for improved processing of Lafun, an African fermented cassava food product, Journal of Applied Microbiology, 109(4), pp. $1402-1410$, DOI: $10.111 / \mathrm{j} .1365-2672.2010 .04769 . \mathrm{x}$

31. Rose-Monde, M., Séverin, K. K., Eric, E. A., Cathérine, D., N'zué, B.and Sébastien, N. L. (2009), Physico-chemical and biochemical characteristics of improved cassava varieties in Cote d'Ivoire, Journal of Animal and Plant Science, 5(2), pp. 507-514.

32. Sanni L.O., Maziya-Dixo B., Akanya C.I., Alaya Y., Egwuonwu C.V., Okechukwu R.U., Ezedinma C., Akoroda M., Lemchi J., Ogbe F., Okoro E., Tarawali G., Mkumbira J., Patino M., Ssemakula G., Dixon A. (2005), Standards for cassava products and guidelines for export, International Institute of Tropical Agriculture, Ibadan, Nigeria. pp. 11-39.

33. Sanni L.O., Adebowale A.A., Awoyale W., Fetuga G.O. (2008), Quality of gari (roasted cassava mash) in Lagos State, Nigeria, Nigerian Food Journal, 26, pp. 125130, DOI: 10.4314/nifoj.v26i2.47446.

34. Sanni L.O., Ikuomola D.P., Sanni S.A., (2001), Effect of length of fermentation and varieties on the quality sweet potato gari, Proceedings of the 8th Triennial Symposium of International Society for Tropical Root Crops-African Branch, Nov. 12-16, IITA, Ibadan, Nigeria, pp, pp. 208-211.

35. Ukpabi U.J., Ndimele C. (1990), Evaluation of gari production in Imo State Nigeria, Nigerian Food Journal, 8, pp. 105-110. 